\title{
Relative gut lengths of coral reef butterflyfishes (Pisces:
}

\section{Chaetodontidae)}

ML Berumen $^{1,2 *}$, MS Pratchett ${ }^{3}$, BA Goodman ${ }^{4}$

1. Red Sea Research Center, King Abdullah University of Science and Technology,

Thuwal, 23955, Kingdom of Saudi Arabia

2. Biology Department, Woods Hole Oceanographic Institution, Woods Hole, MA, 02543, USA

3. ARC Centre of Excellence for Coral Reef Studies, James Cook University, Townsville, QLD 4811, Australia

4. Department of Ecology and Evolutionary Biology, University of Colorado, Boulder, CO, 80309

*Corresponding author:

Email: michael.berumen@kaust.edu.sa

Phone: +966 544700019

Keywords: Chaetodontidae; corallivory; Papua New Guinea; relative gut length 


\begin{abstract}
Variation in gut length of closely related animals is known to generally be a good predictor of dietary habits. We examined gut length in 28 species of butterflyfishes (Chaetodontidae), which encompass a wide range of dietary types (planktivores, omnivores, corallivores). We found general dietary patterns to be a good predictor of relative gut length, although we found high variation among groups and covariance with body size. The longest gut lengths are found in species that exclusively feed on the living tissue of corals, while the shortest gut length is found in a planktivorous species. Although we tried to control for phylogeny, corallivory has arisen multiple times in this family, confounding our analyses. The butterflyfishes, a speciose family with a wide range of dietary habits, may nonetheless provide an ideal system for future work studying gut physiology associated with specialisation and foraging behaviours.
\end{abstract}




\section{Introduction}

Relative gut lengths of vertebrates have long been studied and compared within and among species (e.g., Al-Hussaini 1949). The most common explanations for relatively longer guts in herbivores focus on the chemical defences of plants (e.g., Levin 1976; Hay and Fenical 1988), the indigestibility of plant fibre (e.g., Stevens 1989; Karasov and Martinez del Rio 2007), or the poor nutritional quality of plants as food. If plants are considered "low quality" foods, then increased relative gut length in herbivores could serve as an adaptation in several possible ways: to increase the amount that can be ingested, to increase the time that food remains in the gut for digestion and absorption, and/or to increase the amount of surface area available for absorption (Karasov and Diamond 1983; Yang and Joern 1994; Starck 2005).

Gut morphologies are also known to be plastic and vary among individuals within a species in relation to different diets (e.g., Raubenheimer and Bassil 2007). For example, numerous studies have demonstrated phenotypic responses to changes in experimental diets (Buddington and Diamond 1987; Starck 2005) and through the course of ontogeny, particularly where diet changes (e.g., Kramer and Bryant 1995a). As a gross method of inter-specific comparisons, however, relative gut lengths have long been widely accepted as an important descriptor of gut morphology and an indicator of dietary composition (Al-Hussaini 1949; Kramer and Bryant 1995b). Among three major families of coral reef fishes, Elliott and Bellwood (2003) found relative gut length to be a reliable predictor of general diet. Potential phylogenetic constraints of gut morphology, however, may confound comparisons of distantly related taxa (Westneat 1995; Elliott and Bellwood 
2003; German and Horn 2006), so care must be taken when selecting study organisms for such comparisons.

Among coral reef fishes, there is great ecological and morphological diversity, and within this group, the butterflyfishes (family: Chaetodontidae) are notable for their diversity of trophic behaviours. General categorisations include planktivores (e.g., Allen et al. 1998), herbivores (e.g., Bouchon-Navaro 1986) and general omnivores (e.g., Bouchon-Navaro 1986). Unique to the butterflyfishes are the large number of species that have facultative or obligate usage of coral tissue as a prey source (see Rotjan and Lewis 2008). Coral-feeders in the genus Chaetodon have attracted a great deal of attention in the context of their role as potential indicator species (e.g., Crosby and Reese 1996), particularly those butterflyfish species that feed obligately and exclusively on corals (e.g., Chaetodon trifascialis, Irons 1989). However, very little work has been done on the nutritional "quality” of diets of coral-feeding fishes (but see Kung and Ciereszko 1985) relative to non-coral food sources. The predicted relationship of gut length for coralfeeders is therefore unclear. Two previous studies examined gut lengths of coral-feeders (Motta 1988; Elliott and Bellwood 2003) and both found that coral-feeding fishes had longer gut lengths than omnivores or herbivores, but neither of these two studies discussed the significance of longer guts in corallivores. The implication, however, is that coral tissue is a nutritionally poor resource (i.e., poorer than algae), and a coral-feeder is thus required to have a longer gut. Corallivorous butterflyfishes, with rare exceptions, do not ingest skeletal carbonate material, and most only remove coral tissue or polyps (Motta 1988). 
Recent detailed studies of butterflyfish diets have revealed marked differences in dietary composition even within broad trophic groups (Berumen et al. 2005; Pratchett 2005, 2007). In particular, the increased resolution of foraging specialisation and selectivity among coral-feeding fishes (e.g., Pratchett 2007; Berumen and Pratchett 2008) greatly enhances our understanding of the dietary preferences and foraging behaviours of the large number of species utilising coral tissue as an obligate food source. Within the obligate coral-feeders, there are varying degrees of specialisation, ranging from specialists targeting one single coral prey species (Irons 1989; Pratchett 2007) to generalists consuming most coral species in given location (Berumen et al. 2005; Pratchett 2005). At our study site in Papua New Guinea, we recorded over thirty species of butterflyfishes representing a wide variety of feeding habits (see Allen et al. (1998) for species' authorities). The diversity of feeding strategies in a suite of such closely related fishes offers the opportunity to ask if gut length serves as an accurate indicator of dietary composition in butterflyfishes. We predict that these fish will conform to the traditional patterns established by previous studies (e.g., Al-Hussaini 1949; Kapoor et al. 1975), with relative gut lengths of planktivores $<$ carnivores $<$ omnivores $<$ herbivores $<$ corallivores (the latter prediction drawn from Motta (1988) and Elliott and Bellwood (2003)).

\section{Materials and methods}

Individual butterflyfishes were collected using hand spears on reefs in Kimbe Bay, Papua New Guinea $\left(5^{\circ} \mathrm{S}, 151^{\circ} \mathrm{E}\right)$, between February and April of 2007. To avoid potentially confounding ontogenetic shifts, only adult fishes were collected. The total length of each 
fish was measured to the nearest mm. The alimentary tract was dissected out and the full unstretched gut length from the pyloric duct to the rectum was measured to the nearest mm. The relative gut length was then calculated as a ratio of gut length to body length. Univariate ANOVA was conducted for 26 species (Chaetodon bennetti and Chaetodon unimaculatus were excluded since $\mathrm{n}=1$ for these species). To examine the data for isometry (sensu Raubenheimer 1995), we used analysis of covariance (ANCOVA). Except where noted, all statistical procedures were conducted using R (R Development Core Team 2010).

We grouped our study species into five feeding guilds following Pratchett (2005). Where sufficient dietary information was not available, we classified species into an “unknown” dietary guild. Univariate ANOVA was conducted for the five known dietary guilds. Although we are aware of geographic variation in the feeding habits of some butterflyfish species (e.g., C. unimaculatus, Cox 1994 cf. Pratchett 2005), the categorisations we use here are based on the northern Great Barrier Reef, geographically similar to our study site in Papua New Guinea. Nonetheless, these broad groupings are subject to geographic variation.

As related species do not necessarily represent statistically independent data, comparisons involving conventional statistics may be invalid (Felsenstein 1985; Harvey and Pagel 1991). We tested our results for a significant phylogenetic signal (Freckleton et al. 2002; Garland et al. 2005) using the program PHYSIG.M in MatLab ${ }^{\circledR}$ (Blomberg et al. 2003). This program generates a descriptive statistic $K$ that provides an index of the 
amount of phylogenetic signal within a trait based on the Brownian motion model of evolution for a given phylogenetic tree with known topology and branch lengths (Blomberg et al. 2003). $\mathrm{K}$-values equal to 1 indicate that a trait shows an expected amount of phylogenetic signal, whereas $K$-values less than 1 indicate a trait has less signal than expected and values of $K$ greater than 1 suggest there is more phylogenetic signal than expected. This approach performs 1000 randomisations on the current 'bestestimate' phylogeny and reports $K$-values for each trait of interest (Blomberg et al. 2003). These phylogenetic analyses were undertaken using a pruned phylogeny of a recent molecular phylogeny of the butterflyfishes (Fessler and Westneat 2007) (Fig. 1). This phylogeny included 27/28 species examined in this study. Chaetodon lunulatus, used in our study, was not used in the molecular phylogeny, and subsequently, we substituted the sibling species Chaetodon trifasciatus, which appears to be ecologically and morphologically indistinguishable except for minor color variations (Kuiter 1995, 2002).

\section{Results and Discussion}

Gut length appears to be a useful predictor of general dietary type in the butterflyfishes. Overall, corallivores had much longer guts (relative to total length) than generalists, noncorallivores, and planktivores, which is consistent with previous work in coral reef fishes (Elliott and Bellwood 2003). Variations in relative gut length were significantly different (ANOVA, $d f=25 / 115, F=36.607, P<0.001$ ) among the study species (Fig. 2). Relative gut lengths did vary among broad feeding guilds (ANOVA, $d f=4 / 96, F=11.573, P<$ 
0.001) and fishes which feed exclusively on either hard or soft corals had the longest gut lengths (Fig. 3). This makes it possible to speculate on the diet of species currently categorized as "unknown”. For example, Forcipiger flavissimus appears to fall squarely into the category of non-coral feeders, while Heniochus singularis may potentially be a generalist or feeding on soft corals. These species would make interesting test cases for further research. A significant effect of body size on gut length was also found (ANCOVA, $d f=9 / 91, F=25.04, P<0.001$ ) indicating that some differences in gut length may arise allometrically and may not solely be the result of dietary habits.

The exact nutritional reasons that longer guts may be needed by coral-feeding butterflyfishes is unclear, and future work in this area would be informative. It is possible that the guts of corallivorous fishes must be longer to facilitate effective handling of defensive secondary metabolites known to be in the tissues of some soft corals (Alino et al.1992) and hard corals (e.g., Gochfeld 2004). The species with the longest gut of all the butterflyfishes studied herein belonged to Chaetodon ornatissimus, which is reported to feed on coral mucus (Coles and Strathman 1973). Such a long gut may be necessary to facilitate the processing of the complex polysaccharides in this mucus. Gregson et al. (2008) found that corallivores had the highest bite rates among the Chaetodontidae, suggesting that coral tissue may be of lower nutritional value than prey items consumed by non-corallivores. Additional considerations, such as biotransformation enzymes (e.g., DeBusk et al. 2008) and the presence of algal symbiont material in coral tissue, represent areas where further work could help to answer questions about the nutritional ecology of corallivory. Resolution of these questions will require experimental testing of the 
nutritional requirements and further analysis of digestion and utilisation of nutrients in the gut (sensu Raubenheimer and Bassil 2007).

Phylogenetic analyses reveal that phylogeny is a significant factor in the differences of relative gut length among butterflyfish species (overall observed estimated $K$ of $1.0703, P=0.003$ ), based on the phylogenetic relationships established by Fessler and Westneat (2007). It is important to consider, therefore, the role that evolutionary history has played in determining the relative gut length of these fish (see also Elliott and Bellwood 2003). Corallivory as a feeding mode appears to have independently arisen in this group multiple times (Bellwood et al. 2010), so we must acknowledge that phylogenetic effects may further confound the dietary influence on gut length in this family.

In conclusion, we found that obligate hard- and soft-corallivore species have the longest relative gut lengths. Further interpretation of these results must be applied cautiously as potentially confounding effects of phylogeny and allometry are present. These factors could possibly be resolved by further investigation of a larger number of butterflyfish species selected to include more species that are approximately the same size (and thus reducing the problem of allometric scaling) or that represent a more comprehensive set of phylogenetic groups (to determine if gut length is varying independently of phylogeny). However, this diverse group of fishes provides an ideal opportunity for further research on the nutritional ecology of corallivory and future work 
could shed light on the underlying mechanisms leading to or enabling dietary

specialisation.

\section{Acknowledgements}

This project was funded in part by a National Science Foundation (USA) Graduate

Research Fellowship to MLB.

\section{References}

Al-Hussaini AH (1949) On the functional morphology of the alimentary tract of some fish in relation to differences in their feeding habits: anatomy and histology. Quarterly Journal of Microscopical Science s3-90: 109-139

Alino P, Coll J, Sammarco P (1992) Toxic prey discrimination in a highly specialized predator Chaetodon melannotus (Block et Schneider): visual vs. chemical cues. J Exp Mar Biol 164: 209-220

Allen GR, Steene R, Allen M (1998) A guide to angelfishes and butterflyfishes. Odyssey Publishing, Perth

Bellwood DR, Klanten S, Cowman PF, Pratchett MS, Konow N, van Herwerden L (2010) Evolutionary history of the butterflyfishes (f: Chaetodontidae) and the rise of coral feeding fishes. J Evol Biol 23:335-349

Berumen ML, Pratchett MS (2008) Trade-offs associated with dietary specialization for corallivorous butterflyfishes (Chaetodontidae: Chaetodon). Behav Ecol Sociobiol 62: 989-994

Berumen ML, Pratchett MS, McCormick MI (2005) Within-reef differences in diet and body condition of coral-feeding butterflyfishes (Chaetodontidae). Mar Ecol Prog Ser 287: 217227

Blomberg SP, Garland T, Ives AR (2003) Testing for phylogenetic signal in comparative data: Behavioral traits are more labile. Evolution 57: 717-745

Bouchon-Navaro Y (1986) Partitioning of food and space resources by chaetodontid fishes on coral reefs. J Exp Mar Biol Ecol 103: 21-40

Buddington RK, Diamond JM (1987) Pyloric ceca of fish: a "new” absorptive organ. Am J Physiol 252: G65-G76

Coles SL, Strathmann R (1973) Observations on coral mucus "flocs" and their potential trophic significance. Limnol Oceanogr 18: 673-678

Cox E (1994) Resource use by corallivorous butterflyfishes (Family Chaetodontidae) in Hawaii. Bull Mar Sci 54:535-545

Crosby MP, Reese ES (1996) A manual for monitoring coral reefs with indicator species: butterflyfishes as indicators of change on Indo Pacific reefs. Office of Ocean and Coastal Resource Management, National Oceanic and Atmospheric Administration, Silver 
Spring, Maryland

DeBusk BC, Slattery M, Ki J-S, Lee J-S, Aparicio-Fabre R, Schlenk D (2008) Species differences and effects of soft coral extracts from Sinnularia maximus on the expression of cytochrome P4501A and 2N in butterflyfishes (Chaetodon spp.). Fish Physiol Biochem 34:483-492

Elliott JP, Bellwood DR (2003) Alimentary tract morphology and diet in three coral reef fish families. J Fish Biol 63: 1598-1609

Felsenstein J (1985) Phylogenies and the comparative method. Am Nat 126: 1-25

Fessler JL, Westneat MW (2007) Molecular phylogenetics of the butterflyfishes (Chaetodontidae): Taxonomy and biogeography of a global coral reef fish family. Mol Phylog Evol 45: 50-68

Freckleton RP, Harvey PH, Pagel M (2002) Phylogenetic analysis and comparative data: a test and review of evidence. Am Nat 160: 712-726

Garland TJ, Bennett AF, Rezende EL (2005) Phylogenetic approaches in comparative physiology. J Exp Biol 208: 3015-3035

German DP, Horn MH (2006) Gut length and mass in herbivorous and carnivorous prickleback fishes (Teleostei: Stichaeidae): ontogenetic, dietary, and phylogenetic effects. Mar Biol 148: $1123-1134$

Gochfeld DJ (2004) Predation-induced morphological and behavioral defenses in a hard coral: implications for foraging behavior of coral-feeding butterflyfishes. Mar Ecol Prog Ser 267: 145-158

Gregson MA, Pratchett MS, Berumen ML, Goodman BA (2008) Relationships between butterflyfish (Chaetodontidae) feeding rates and coral consumption on the Great Barrier Reef. Coral Reefs 27: 583-591

Harvey P, Pagel M (1991) The comparative method in evolutionary biology. Oxford University Press, Oxford

Hay ME, Fenical W (1988) Marine plant-herbivore interactions: The ecology of chemical defense. Annu Rev Ecol Syst 19: 111-145

Irons DK (1989) Temporal and areal feeding behaviour of the butterflyfish, Chaetodon trifascialis, at Johnston Atoll. Environ Biol Fishes 25: 187-193

Kapoor BG, Smit H, Verighina IA (1975) The alimentary canal and digestion in teleosts. Adv Mar Biol 13: 109-300

Karasov WH, Diamond JM (1983) Adaptive regulation of sugar and amino acid transport by vertebrate intestine. Am J Physiol 245: G443-G462

Karasov WH, Martínez del Rio C (2007) Physiological ecology: how animals process energy, nutrients, and toxins. Princeton University Press, Princeton, New Jersey

Kramer DL, Bryant MJ (1995a) Intestine length in the fishes of a tropical stream: 1. Ontogenetic allometry. Environ Biol Fishes 42: 115-127

Kramer DL, Bryant MJ (1995b) Intestine length in the fishes of a tropical stream: 2. Relationships to diet - the long and short of a convoluted issue. Environ Biol Fish 42: 129-141

Kuiter RH (1995) Chaetodon lunulatus, a sibling species of C. trifasciatus, with observations on other sibling species of butterflyfish (Chaetodontidae). Revue Francaise d'Aquariologie 21: $105-106$

Kuiter RH (2002) Butterflyfishes, bannerfishes and their relatives - a comprehensive guide to the Chaetodontidae \& Microcanthidae. TMC Publishing, Chorleywood, UK 
Kung S-S, Ciereszko LS (1985) Occurrence of the wax cetyl palmitate in stomachs of the corallivorous butterfly fish Chaetodon trifascialis. Coral Reefs 4: 45-46

Levin DA (1976) The chemical defenses of plants to pathogens and herbivores. Annu Rev Ecol Syst 7: 121-159

Motta PJ (1988) Functional morphology of the feeding apparatus of ten species of Pacific butterflyfishes (Perciformes, Chaetodontidae): an ecomorphological approach. Environ Biol Fish 22: 39-67

Pratchett MS (2005) Dietary overlap among coral-feeding butterflyfishes (Chaetodontidae) at Lizard Island, northern Great Barrier Reef. Mar Biol 148: 373-382

Pratchett MS (2007) Dietary selection by coral-feeding butterflyfishes (Chaetodontidae) on the Great Barrier Reef, Australia. Raffles Bull Zool S14: 161-166

R Development Core Team (2010). R: A language and environment for statistical computing. R Foundation for Statistical Computing, Vienna, Austria. ISBN 3-900051-07-0, URL http://www.R-project.org.

Raubenheimer D (1995) Problems with ratio analysis in nutritional studies. Func Ecol 9:21-29

Raubenheimer D, Bassil K (2007) Separate effects of macronutrient concentration and balance on plastic gut responses in locusts. J Comp Physiol B 177: 849-855

Rotjan RD, Lewis SM (2008) Impact of coral predators on tropical reefs. Mar Ecol Prog Ser 367: 73-91

Starck JM (2005) Structural flexibility of the digestive system of tetrapods - patterns and processes at the cellular and tissue level. In: Starck JM, Wang T (eds) Physiological and ecological adaptations to feeding in vertebrates. Science Publishers, Enfield, pp 175-200

Stevens CE (1989) Evolution of vertebrate herbivores. Acta Veterinaria Scandinavica Supplementum (Denmark) 86: 9-19

Westneat MW (1995) Feeding, function and phylogeny: analysis of historical biomechanics in labrid fishes using comparative methods. Syst Biol 44: 361-383

Yang Y, Joern A (1994) Gut size changes in relation to variable food quality and body size in grasshoppers. Func Ecol 8: 36-45 
Figure 1. Pruned phylogeny of a recent molecular phylogeny of the butterflyfishes (Fessler and Westneat 2007). This phylogeny included 27 of 28 species examined in this study. Chaetodon lunulatus, used in our study, was not used in the molecular phylogeny, and subsequently the sibling species Chaetodon trifasciatus (Kuiter 1995) was substituted. Species are assigned into one of five feeding guilds (following Pratchett 2005): NC = Non-coral feeder (almost never feeding on hard or soft corals), OC = Obligate hard coral feeder (almost exclusively feeding on hard corals), SC = Soft coral feeder, $G=$ Generalist (often feeding on hard or soft corals, but with a significant portion of diet from non-coral sources), $\mathrm{P}=$ Planktivore. The exact diets for four species are unknown and are noted with a "U”.

Figure 2. Mean relative gut lengths for 28 species of butterflyfishes from Kimbe Bay, Papua New Guinea. Relative gut length is calculated as the ratio of full unstretched gut length (mm) to the total length of the fish (mm) and is shown \pm S.E. The number in parentheses indicates sample size for each species. Bar color indicates one of five feeding guilds (where known). Dashed vertical lines indicate groupings of homogenous subsets identified using Tukey’s post-hoc test.

Figure 3. Mean relative gut lengths of various dietary categories of butterflyfishes from Kimbe Bay, Papua New Guinea. Bars represent the mean relative gut length (the ratio of full unstretched gut length (mm) to the total length of the fish $(\mathrm{mm})$ ) and is shown \pm S.E. Dashed horizontal lines indicate groupings of homogenous subsets identified using Tukey’s post-hoc test. 


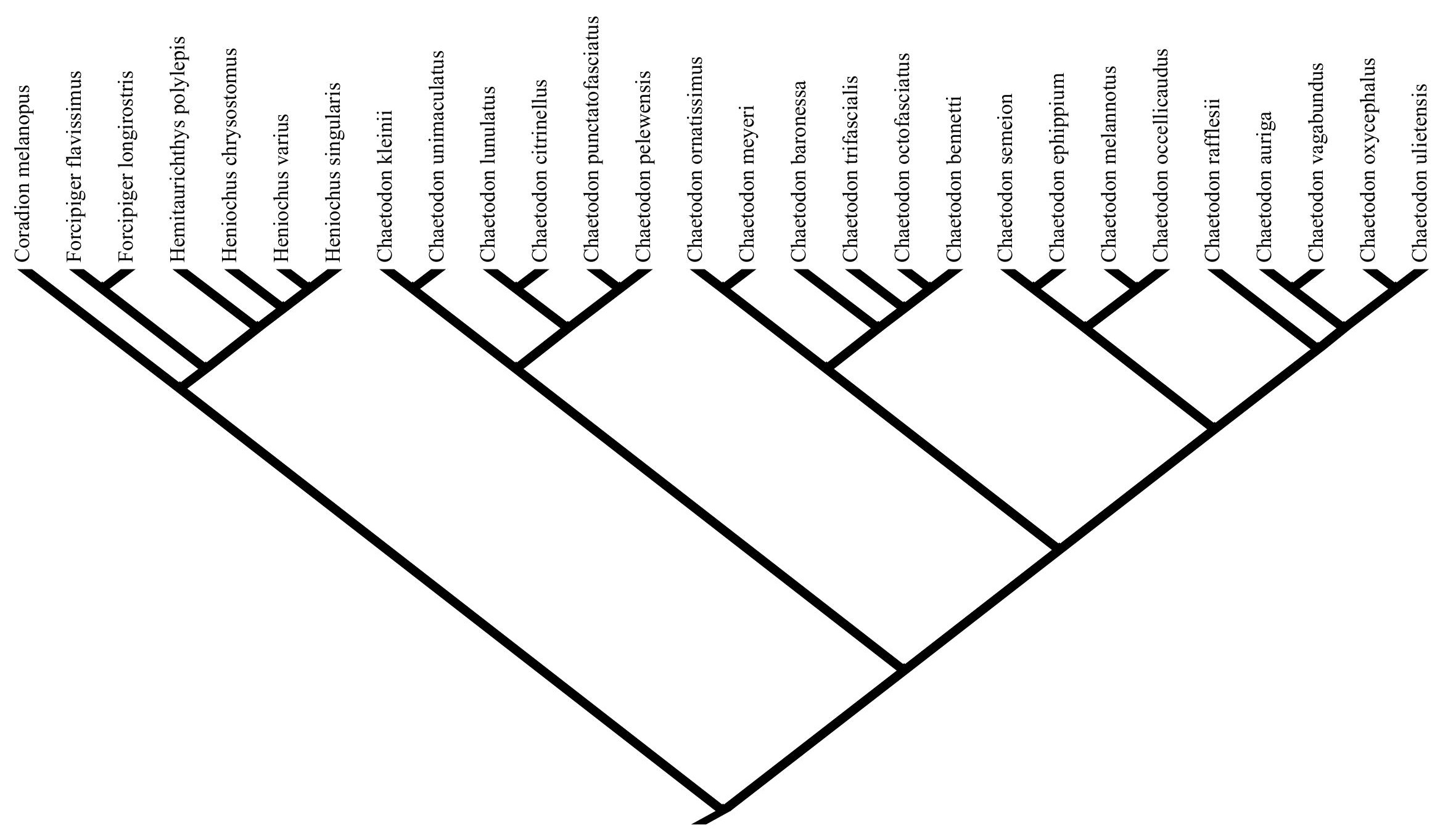




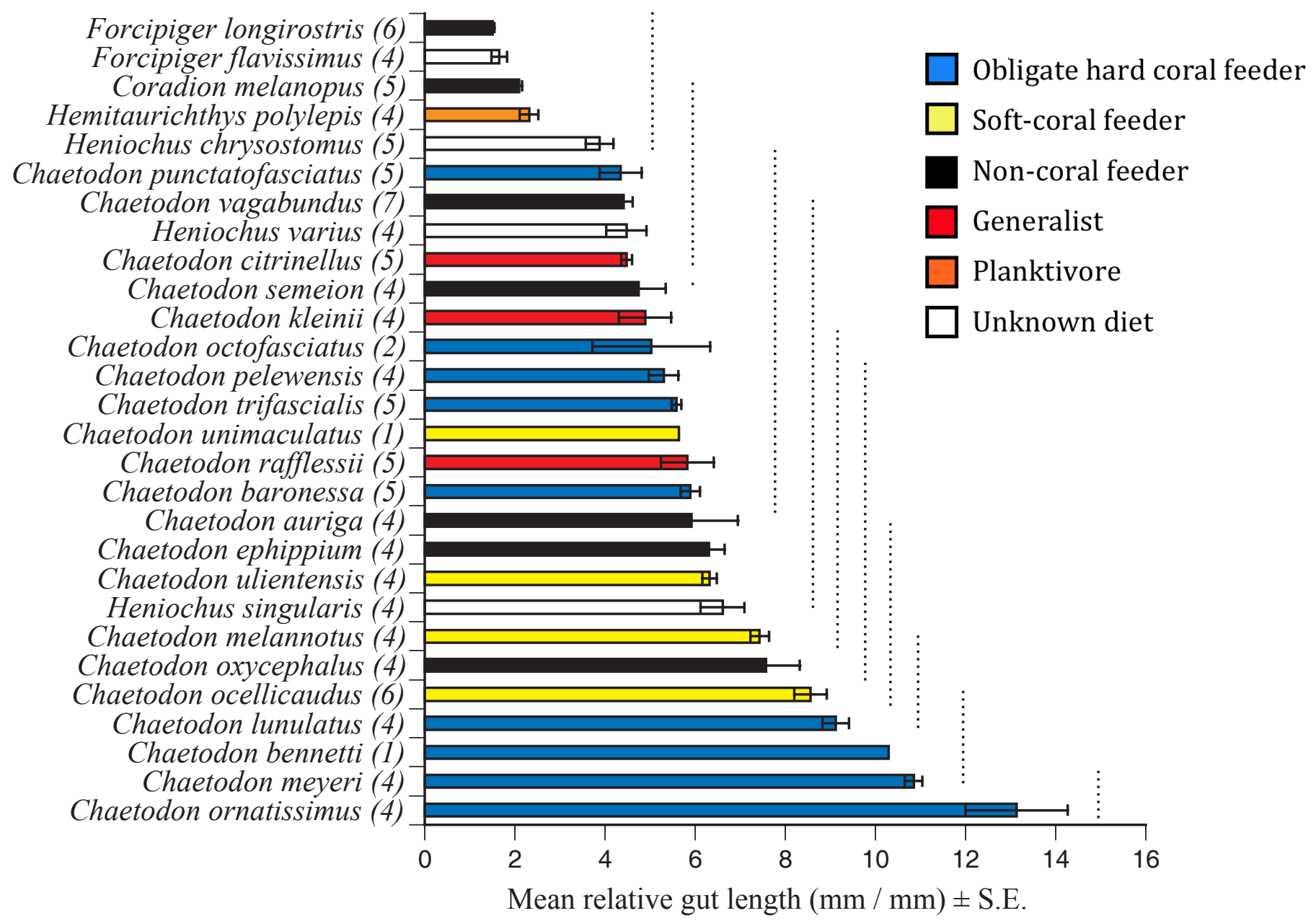




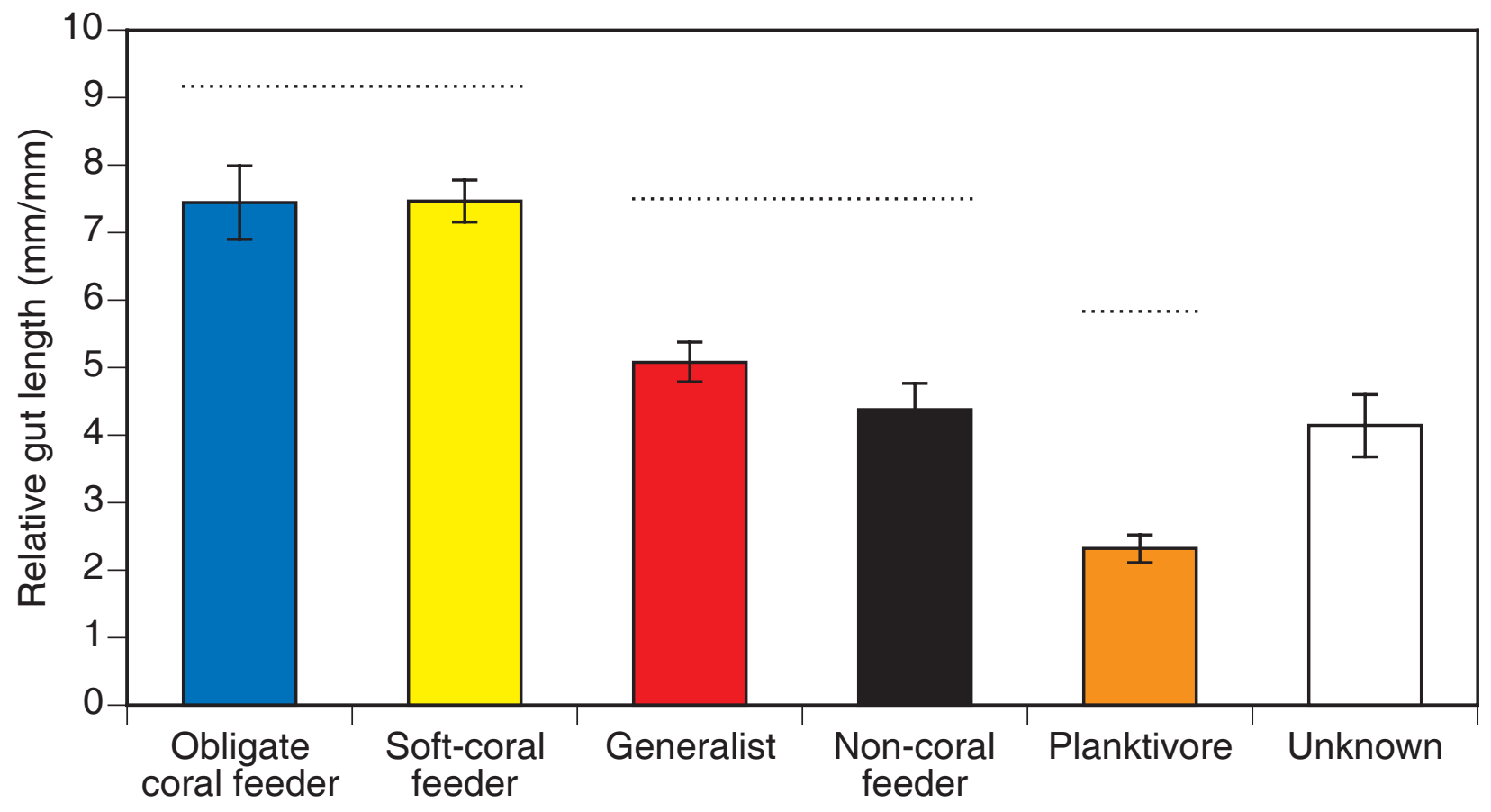

